\title{
Evaluation of Gamma Nails in Intertrochanteric Fractures of Femur and Modified Technique for Removal
}

\author{
Baran Kömür1', Erdem Kaan², Bariş Yilmaz³, Güzelali Özdemir³, Tahir Mutlu Duymuş \\ ${ }^{1}$ Kanuni Sultan Süleyman Training and Research Hospital, Istanbul, Turkey \\ ${ }^{2}$ Dr. Ersin Arslan State Hospital, Gaziantep, Turkey \\ ${ }^{3}$ Fatih Sultan Mehmet Training and Research Hospital, Istanbul, Turkey \\ Email: ${ }^{*}$ barankomur@gmail.com
}

Received 22 November 2015; accepted 12 December 2015; published 11 December 2015

Copyright (C) 2015 by authors and OALib.

This work is licensed under the Creative Commons Attribution International License (CC BY).

http://creativecommons.org/licenses/by/4.0/

(c) (i) Open Access

\begin{abstract}
Intertrochanteric fractures of femur (IFF) that comprise 8\% - 10\% of all fractures are most commonly seen in people over 65 years old. Fractures of this region not only affect general state of health of patients, but also affect their lives mentally, socially and economically. Sufficient reduction and rigid internal fixation are still the best method for unstable IFF. Because of its biomechanical and anatomical design, proximal femoral nail (PFN) is a fixation material that has started to be increasingly used by orthopedic surgeons recently. In orthopedic traumatic surgery, implant failure is one of the most serious complications. To avoid these complications, many surgical techniques have been reported. Break of intramedullary nails especially in case of a nonunion requires to be extracted, which is a very difficult and challenging procedure for the surgeon. Many methods and materials have been described for this procedure. In this study we aim to review these topics.
\end{abstract}

\section{Keywords}

Gamma Nails, Intertrochanteric, Femur, Removal

Subject Areas: Surgery \& Surgical Specialties

\section{Introduction}

Intertrochanteric fractures of femur (IFF) that comprise $8 \%-10 \%$ of all fractures are most commonly seen in people over 65 years old [1]. The most common causes of intertrochanteric femur fractures in this population

${ }^{*}$ Corresponding author.

How to cite this paper: Kömür, B., Kaan, E., Yilmaz, B., Özdemir, G. and Duymuş, T.M. (2015) Evaluation of Gamma Nails in Intertrochanteric Fractures of Femurand Modified Technique for Removal. Open Access Library Journal, 2: e2174.

http://dx.doi.org/10.4236/oalib.1102174 
can be outlined as: simple falls, osteoporosis and the propensity of older patients to fall due to decline in physical capacity, accompanying systemic diseases, visual and auditory losses, weakening of reflexes at that age group; function of avoidance behavior against environmental dangers is getting weakened. Elder people are exposed to simple falls due to loss of balance, faltering, slipping and stumbling which are caused by drugs that are taken together and simple traumas such as fall while standing up from seat, fall while going downstairs. Additionally, decrease in bony mass elderly leads to segmental unstable intertrochanteric fractures of femur even by simple traumas [1] [2].

\section{Distribution and Evaluation}

Fractures of this region not only affect general state of health of patients, but also affect their lives mentally, socially and economically. Despite the developed patient care and operational techniques recently, results of these fractures may be worse than expected. Intertrochanteric fractures of femur are among important causes that increase the mortality and morbidity in elder patients [3].

Bone quality not to be good and presence of accompanying systemic disorders can be controversial in choice of appropriate treatment in these patients [4]. Aim of the treatment of pelvic fractures occurring in elder people is to turn them back to their lives before the fracture by making them walk as soon as possible and to prevent development of complications due to physical inactivity that can lead to death [1] [3] [4].

Sufficient reduction and rigid internal fixation are still the best methods for unstable IFF. Because of its biomechanical and anatomical design, proximal femoral nail (PFN) is a fixation material that has started to be increasingly used by orthopedic surgeons recently. However, the use of rigid fixation methods and problems with implant following operation are troublesome because of accompany of osteoporosis in unstable fractures in elder patient group [5] [6].

In many studies, treatment results of fractures of intertrochanteric region by using different internal fixation methods have been compared [7] [8]. As a result of these studies, inefficacy rates varying between $7 \%-53 \%$ have been reported. Whereas the least inefficacy has developed in AO and dynamic sliding nails, the most inefficacy has been observed in Mc Laughlin and Jewett plates. As various technical difficulties can be encountered in osteoporotic cases which are applied proximal femoral nailing, it has been declared that complications in cases which are performed intramedullary nailing are still very common and hemiarthroplasty is still a good alternative method [9] [10].

\section{Complications}

Collapse related to secondary varus and lateral migration of screws have been reported in high incidence. In various studies, cut-out of screws reaches to $10 \%$ [11].

Screwing at wrong position or not screwing with appropriate length of pelvic screws or insufficient reduction are held responsible for possible striping in PFN nails. Screwing 5 - $10 \mathrm{~mm}$ till the subchondral bone is recommended by Wang et al. [12].

Femoral fracture at distal of PFN is a rarer complication. Commonly it is encountered in use of gamma nail [13]. Banan et al. have reported in two of 46 cases and Fogagnolo et al. in one of 47 cases development of femoral diaphysial fracture from distal part of nail [14] [15]. Tyllianakis et al. has reported implant fracture at the level of distal locking screw in two cases [16]. Rappold et al. has determined implant fracture at the level of the hole of neck [17].

In orthopedic traumatic surgery, implant failure is one of the most serious complications. To avoid of these complications, many surgical techniques have been reported [18] [19].

It has been presumed that the incidence of pelvic fractures will increase in the future [20] [21]. Intertrochanteric fractures that are described in pelvic fractures are more commonly seen elderly and are caused by lowpower injury mechanisms. Risk factors for intertrochanteric fractures are gender, osteoporosis, history of falling and walking abnormalities [22].

Mortality rate in the first year following pelvic fractures have been reported as to be between $20 \%$ and $25 \%$. Markers for mortality in the first year following pelvic fractures are: malnutrition, age of $>85$, dependency to daily routines, ASA 3 or 4 and development of postoperative complication [2] [3]. Medical complications rates have been reported to be between $10 \%$ and $40 \%$ in the literature. For decreasing medical complications and high mortality rate, early ambulation is one of the most effective method [23]-[25]. On this direction, these cases 
should be operated as soon as possible when optimal conditions are achieved (Table 1).

Various implants have been designed in order to be used in surgery of proximal femoral fractures. Cephalomedullary nails which are one of them have been increasingly preferred for treatment of proximal femoral fracture [26]. For fixation of unstable trochanteric fractures, clinical and biomechanical superiority of cephalomedullary nails have been shown [27]-[30]. Cephalomedullary nails have advantages such as application through a small incision, minimal blood loss and short operation time [30]-[33]. In addition to that, malunion and fracture collapse have been observed less commonly in cephalomedullary nails compared to extramedullary systems [34].

Break of gamma nail is an extremely rare complication and is reported to be between $0.2 \%$ and $5.7 \%$ [35]-[38]. Nonunion is thought to be the primary cause in this complication [38]. Majority of complications which are seen after fixation with gamma nail can be prevented by application of routine rules [39]. Most common site of break in nail is the entrance of the femoral head screw which is the weakest point. Other points are holes of distal locking screws.

Break of intramedullary nails especially in case of a nonunion requires to be extracted, which is very difficult and challenging procedure for the surgeon. Many methods and materials have been described for this procedure. Mandrel devices, percutaneous osteotomes, hook rods, Kuntcher groovers, circlage wire, laparoscopic forcepses can be counted as various devices used for this procedure [40]. Riansuwan et al. have described an alternative procedure for extraction of broken gamma nail. With this method broken fragment inside the channel was extracted successfully and no complication occurred [19]. Steinberg et al. was applied a method by which distal fragment of broken intramedullary nail inside channel can be extracted without requiring an additional approach to bone, without using any special equipment or device and without any damage to channel [40]. Abdelgawad et $a l$. has divided the methods that are being used up to today for extraction of broken nails and has described a new method for extraction of nail stuck in the narrow channel in a study published in 2013 [41].

\section{Conclusions}

All in all, intertrochanteric fractures of femur are commonly seen in people over 65 years old and comprise $8 \%$ $10 \%$ of all fractures. In people in this age group, as a result of weakening of function of avoidance behaviour due to decline in physical capacity, accompanying systemic diseases, visual and auditory losses, weakening of reflexes, function of avoidance behavioral against environmental dangers, pelvic fractures occur because of simple traumas due to loss of balance, faltering, slipping and stumbling, fall while standing up from seat, fall while going downstairs. Also, decrease in bony mass elderly leads to segmental unstable intertrochanteric fractures of femur even by simple traumas. These fractures are among important causes that increase mortality and morbidity.

Sufficient reduction and rigid internal fixation are still the best methods for unstable IFF and the most commonly used implants are Gamma nails or proximal femoral nail (PFN). Along with this, because of accompanying of osteoporosis to unstable fracture, difficulties during and after operation and implant failures can be encountered in the use of rigid fixation methods. One of these complications is break of placed PFN or gamma nail.

Table 1. Operation methods, advantages and disadvantages and prognosis in intertrochanteric femur fractures.

\begin{tabular}{|c|c|c|c|}
\hline & Advantages & Disadvantages & Prognosis \\
\hline $\begin{array}{l}\text { Unilateral } \\
\text { external } \\
\text { fixation }\end{array}$ & $\begin{array}{l}\text { - } \quad \text { operation time is less } \\
\text { - } \quad \text { inexpensive } \\
\text { reduced time in the hospital }\end{array}$ & $\begin{array}{l}\text { - } \quad \text { pin tract infection } \\
\text { - } \quad \text { prolonged union time } \\
\text { - } \text { increased incidence of varus position } \\
\text { of the fracture site } \\
\text { - inferior functional outcome }\end{array}$ & $\begin{array}{l}\text { - } \text { good in stable fractures } \\
\text { - } \quad \text { poor in unstable fractures }\end{array}$ \\
\hline $\begin{array}{l}\text { Dynamic } \\
\text { hip screw }\end{array}$ & $\begin{array}{l}\text { - } \quad \text { rigid fixation } \\
\text { - } \text { good compression of the fracture site }\end{array}$ & $\begin{array}{l}\text { - } \quad \text { the incision length } \\
\text { - } \quad \text { operation time } \\
\text { - } \quad \text { blood loss and drainage }\end{array}$ & \\
\hline $\begin{array}{l}\text { Gamma } \\
\text { nail }\end{array}$ & $\begin{array}{l}\text { - } \quad \text { earlier rehabilitation } \\
\text { - } \quad \text { the recovery of hip joint function is better } \\
\text { - } \text { the incidence of complications is less less } \\
\text { - less blood loss } \\
\text { - } \quad \text { early weight-bearing }\end{array}$ & $\begin{array}{ll}\text { - } & \text { screw cut-out } \\
\text { - } & \text { implant failure } \\
\text { - } & \text { high cost of implant }\end{array}$ & \\
\hline
\end{tabular}


Most common site of break in nail is the entrance of the neck screw which is the weakest point. Other points are holes of distal locking screws. Break of intramedullary nails especially in case of a nonunion requires to be extracted. Because this procedure is a very difficult and challenging procedure for the surgeon, many studies concerning that have been conducted, and many devices and methods have been tried. Despite this, nowadays, extraction of intramedullary nails through channel is still encountered as a difficult and challenging procedure for surgeons.

\section{References}

[1] Vossinakis, I.C. and Badras, L.S. (2002) The External Fixator Compared with the Sliding Hip Screw for Pertrochnateric Fractures of the Femur. The Bone \& Joint Journal, 84, 23-29. http://dx.doi.org/10.1302/0301-620X.84B1.12034

[2] Aharonoff, G.B., Koval, K.J., Skovron, M.L. and Zuckerman, J.D. (1997) Hip Fractures in the Elderly: Predictors of One Year Mortality. Journal of Orthopaedic Trauma, 11, 162-165. http://dx.doi.org/10.1097/00005131-199704000-00004

[3] Koval, K.J., Maurer, S.G., Su, E.T., Aharonoff, G.B. and Zuckerman, J.D. (1999) The Effects of Nutritional Status on Outcome after Hip Fracture. J Orthop Trauma, 13, 164-169. http://dx.doi.org/10.1097/00005131-199903000-00003

[4] Lorich, D.G., Geller, D.S. and Nielson, J.H. (2004) Osteoporotic Pertrochanteric Hip Fractures: Management and Current Controversies. The Journal of Bone \& Joint Surgery, 86, 398-410.

[5] Hwang, J.H., Oh, J.K., Han, S.H., Shon, W.Y. and Oh, C.W. (2008) Mismatch between PFNa and Medullary Canal Causing Difficulty in Nailing of the Pertrochanteric Fractures. Archives of Orthopaedic and Trauma Surgery, 12, 1443-1446. http://dx.doi.org/10.1007/s00402-008-0736-1

[6] Bonnaire, F., Weber, A., Bösl, O., Eckhardt, C., Schwieger, K. and Linke, B. (2007) “Cutting out” in Pertrochanteric Fractures-Problem of Osteoporosis? Der Unfallchirurg, 110, 425-432. http://dx.doi.org/10.1007/s00113-007-1248-0

[7] Koval, K.J., Chen, A.L., Aharonoff, G.B., Egol, K.A. and Zuckerman, J.D. (2004) Clinical Pathway for Hip Fractures in the Elderly. Clinical Orthopaedics and Related Research, 425, 72-81.

[8] Bridle, S.H., Patel, A.D., Bircher, M. and Calvert, P.T. (1991) Fixation of Intertrochanteric Fractures of the Femur. A Randomised Prospective Comparison of the Gamma Nail and the Dynamic Hip Screw. The Journal of Bone \& Joint Surgery (British Volume), 73, 330-334.

[9] Jensen, J.S., Sonne-Holm, S. and Tandevold, E. (1980) Unstable Intertrochanteric Fractures: A Comparative Analysis of Four Methods of Internal Fixation. Acta Orthopaedica Scandinavica, 51, 949-962. http://dx.doi.org/10.3109/17453678008990900

[10] Hardy, D.C.R., Descamps, P.Y., Krallis, P., Fabeck, L., Smets, P., Bertens, C.L. and Delince, P.E. (1998) Use of an Intramedullary Hip-Screw Compared with a Compression Hip-Screw with a Plate for Intertrochanteric Femoral Fractures. The Journal of Bone \& Joint Surgery (American Volume), 80, 618-630.

[11] Boldin, C., Seibert, F.J., Fankhauser, F., Peicha, G., Grechenig, W. and Szyszkowitz, R. (2003) The Proximal Femoral Nail (PFN)_A Minimal Invasive Treatment of Unstable Proximal Femoral Fractures: A Prospective Study of 55 Patients with a Follow-Up of 15 Months. Acta Orthopaedica Scandinavica, 74, 53-58. http://dx.doi.org/10.1080/00016470310013662

[12] Wang, C.J., Brown, C.J., Yettram, A.L. and Procter, P. (2000) Intramedullary Femoral Nails: One or Two Lag Screws? A Preliminary Study. Medical Engineering \& Physics, 22, 613-624. http://dx.doi.org/10.1016/S1350-4533(00)00081-3

[13] Simmermacher, R.K., Bosch, A.M. and Van der Werken, C. (1999) The AO/ASIF-Proximal Femoral Nail (PFN): A New Device for the Treatment of Unstable Proximal Femoral Fractures. Injury, 30, 327-332. http://dx.doi.org/10.1016/S0020-1383(99)00091-1

[14] Banan, H., Al-Sabti, A., Jimulia, T. and Hart, A.J. (2002) The Treatment of Unstable, Extracapsular Hip Fractures with the AO/ASIF Proximal Femoral Nail (PFN)—Our First 60 Cases. Injury, 33, 401-405. http://dx.doi.org/10.1016/S0020-1383(02)00054-2

[15] Fogagnolo, F., Kfuri Jr., M. and Paccola, C.A. (2004) Intramedullary Fixation of Pertrochanteric Hip Fractures with the Short AOASIF Proximal Femoral Nail. Archives of Orthopaedic and Trauma Surgery, 124, 31-37. http://dx.doi.org/10.1007/s00402-003-0586-9

[16] Tyllianakis, M., Panagopoulos, A., Papadopoulos, A., Papasimos, S. and Mousafiris, K. (2004) Treatment of Extracapsular Hip Fractures with the Proximal Femoral Nail (PFN): Long Term Results in 45 Patients. Acta Orthopcdica Belgica, 70, 444-454.

[17] Rappold, G., Hertz, H. and Spitaler, R. (2001) Implant Breakage of the Proximal Femoral Nail (PFN) Reasons and Case Reports. European Journal of Trauma, 27, 333-337. 
[18] Tantigate, D., Riansuwan, K., Mahaisavariya, B. and Sukjaitham, K. (2015) Breakage of a Lag Screw of Cephalomedullary Nail: A Technique of Removal. Clinics in Orthopedic Surgery, 7, 261-263. http://dx.doi.org/10.4055/cios.2015.7.2.261

[19] Riansuwan, K., Carter, C. and Nercessian, O. (2008) Removal of Broken Long Gamma Nail: A Modified Guide Wires Technique. Journal of Trauma, 64, 517-519. http://dx.doi.org/10.1097/TA.0b013e3181469e0f

[20] Cooper, C., Campion, G. and Melton, L.J. (1992) Hip Fractures in the Elderly: A Worldwide Projection. Osteoporosis International, 2, 285-289. http://dx.doi.org/10.1007/BF01623184

[21] Cummings, S.R., Rubin, S.M. and Black, D. (1990) The Future of Hip Fractures in the United States. Numbers, Costs, and Potential Effects of Postmenopausal Estrogen. Clinical Orthopaedics and Related Research, 252, 163-166.

[22] Ahn, J. and Bernstein, J., Eds. (2010) Fractures in Brief. Intertrochanteric Hip Fractures. Clinical Orthopaedics and Related Research, 468, 1450-1452. http://dx.doi.org/10.1007/s11999-010-1263-2

[23] Rogers, F.B., Shackford, S.R. and Keller, M.S. (1995) Early Fixation Reduces Morbidity and Mortality in Elderly Patients with Hip Fractures for Low Impact Falls. Journal of Trauma, 39, 261-265. http://dx.doi.org/10.1097/00005373-199508000-00012

[24] Sircar, P., Godkar, D., Mahgrerefteh, S., et al. (2007) Morbidity and Mortality among Patients with Hip Fractures Surgically Repaired within and after 48 Hours. American Journal of Therapeutics, 14, 508-513. http://dx.doi.org/10.1097/01.pap.0000249906.08602.a6

[25] Wu, Y., Watson, J.T., Kuldjanov, D. and Jackman, J. (2014) Rotationally Stable Fixation for Intertrochanteric Hip Fractures: The Intertan Experience, Surgical Technique, and Outcomes. Techniques in Orthopaedics, 29, 120-132. http://dx.doi.org/10.1097/BTO.0000000000000070

[26] Anglen, J.O. and Weinstein, J.N. (2008) Nail or Plate Fixation of Intertrochanteric Hip Fractures: Changing Pattern of Practice. A Review of the American Board of Orthopaedic Surgery Database. Journal of Bone \& Joint Surgery, 90, 700-707. http://dx.doi.org/10.2106/JBJS.G.00517

[27] Haidukewych, G.J., Israel, T.A. and Berry, D.J. (2001) Reverse Obliquity Fractures of the Intertrochanteric Region of the Femur. Journal of Bone \& Joint Surgery, 83-A, 643-650.

[28] Sadowski, C., Lübbeke, A., Saudan, M., et al. (2002) Treatment of Reverse Oblique and Transverse Intertrochanteric Fractures with Use of an Intramedullary Nail or a 95 Degrees Screw-Plate: A Prospective, Randomized Study. Journal of Bone \& Joint Surgery, 84-A, 372-381.

[29] Haidukewych, G.J. (2009) Intertrochanteric Fractures: Ten Tips to Improve Results. Journal of Bone \& Joint Surgery, 91, 712-719.

[30] Kuzyk, P.R., Lobo, J., Whelan, D., Zdero, R., McKee, M.D. and Schemitsch, E.H. (2009) Biomechanical Evaluation of Extramedullary versus Intramedullary Fixation for Reverse Obliquity Intertrochanteric Fractures. Journal of Orthopaedic Trauma, 23, 31-38. http://dx.doi.org/10.1097/BOT.0b013e318190ea7d

[31] Utrilla, A.L., Reig, J.S., Munoz, F.M. and Tufanisco, C.B. (2005) Trochanteric Gamma Nail and Compression Hip Screw for Trochanteric Fractures: A Randomized, Prospective, Comparative Study in 210 Elderly Patients with a New Design of the Gamma Nail. Journal of Orthopaedic Trauma, 19, 229-233. http://dx.doi.org/10.1097/01.bot.0000151819.95075.ad

[32] Bess, R.J. and Jolly, S.A. (1997) Comparison of Compression Hip Screw and Gamma Nail for Treatment of Peritrochanteric Fractures. Journal of the Southern Orthopaedic Association, 6, 173-179.

[33] Hardy, D.C., Descamps, P.Y., Krallis, P., et al. (1998) Use of an Intramedullary Hip-Screw Compared with a Compression Hip-Screw with a Plate for Intertrochanteric Femoral Fractures. A Prospective, Randomized Study of One Hundred Patients. Journal of Bone \& Joint Surgery, 80, 618-630.

[34] Ahrengart, L., Törnkvist, H., Fornander, P., et al. (2002) A Randomized Study of the Compression Hip Screw and Gamma Nail in 426 Fractures. Clinical Orthopaedics and Related Research, 401, 209-222. http://dx.doi.org/10.1097/00003086-200208000-00024

[35] Gaebler, C., Stanzl-Tschegg, S., Tschegg, E.K., et al. (1999) Implant Failure of the Gamma Nail. Injury, 30, 91-99. http://dx.doi.org/10.1016/S0020-1383(98)00215-0

[36] Pervez, H. and Parker, M.J. (2001) Results of the Long Gamma Nail for Complex Proximal Femoral Fractures. Injury, 32, 704-707. http://dx.doi.org/10.1016/S0020-1383(01)00022-5

[37] Iwakura, T., Niikura, T., Lee, S.Y., et al. (2013) Breakage of a Third Generation Gamma Nail: A Case Report and Review of the Literature. Case Reports in Orthopedics, 2013, Article ID: 172352. http://dx.doi.org/10.1155/2013/172352

[38] Alvarez, D.B., Aparicio, J.P., Fernandez, E.L., Mugica, I.G., Batalla, D.N. and Jimenez, J.P. (2004) Implant Breakage, a Rare Complication with the Gamma Nail: A Review of 843 Fractures of the Proximal Femur Treated with a Gamma Nail. Acta Orthopeedica Belgica, 70, 435-443. 
[39] Hesse, B. and Gächter, A. (2004) Complications Following the Treatment of Trochanteric Fractures with the Gamma Nail. Archives of Orthopaedic and Trauma Surgery, 124, 692-698. http://dx.doi.org/10.1007/s00402-004-0744-8

[40] Steinberg Ely, L., Luger, E., Menahem, A. and Helfet, L.D. (2004) Removal of a Broken Distal Closed Section Intramedullary Nail Report of a Case Using a Simple Method. Journal of Orthopaedic Trauma, 18, 233-235. http://dx.doi.org/10.1097/00005131-200404000-00007

[41] Abdelgawad Amr, A. and Kanlic, E. (2013) Removal of a Broken Cannulated Intramedullary Nail: Review of the Literature and a Case Report of a New Technique. Case Reports in Orthopedics, 2013, Article ID: 461703. 